\title{
Acceptance of Family Planning Methods Among the Married Male of A Selected Rural Area in Bangladesh
}

\author{
Md Moktel Hossain ${ }^{1 *}$ \\ Umme Jamila Akther Manni
}

'Department of Community Medicine Dhaka Medical College, Dhaka, Bangladesh

\section{*Correspondence to:}

\section{Dr. Md Moktel Hossain}

Associate Professor \& Head

Department of Community Medicine

Dhaka Medical College

Dhaka, Bangladesh.

Mobile : +8801912800476

E-mail :drmoktel7@gmail.com

\begin{abstract}
This descriptive study was conducted in Darogarchala, Sreepur Upazilla with a view to assessing the acceptance of contraceptive methods among the married male. Total 325 participants of age ranging from 20 to 60 years were interviewed. The mean age of the respondents was 38.5 years. Maximum 107 (33\%) were in the age group of 30 to 39 years. Majority of the respondents (34\%) were illiterate. Among the rest, 91 (28\%) had primary education, 87 had completed SSC and 26 had completed HSC and 5 were graduate. In the study, it was found that, majority respondents (34\%) were businessmen, $20 \%$ were laborers, $19 \%$ were service holders, $16 \%$ were farmers, and $12 \%$ were unemployed. More than $98 \%$ of the respondents were muslims. Majority $211(65 \%)$ of the family were nuclear family and $114(35 \%)$ were family from joint family. According to monthly income, it was found that, 141 had monthly income in between 1000 taka to 5000 taka, 110 respondents had income in between 5001 to 10000 taka, 33 had income in between 10001 to 15000 taka, 22 had income between 15001 to 20000 taka, and 10 had income between 20000 to 30000 taka. Only a small fraction (2.54\%) earned more than 30000 taka. Maximum (45\%) of the respondents were married between the ages 22 to 24 years. According to number of children, majority of the respondents (74.69\%) had 1 to 3 alive children and $73.23 \%$ wished to have children in the future. 97 of the respondents obtained information from health workers and about $40 \%$ from Radio or TV. Most of the respondents $(66 \%)$ did not use any method of family planning and 33.66\% applied one of the family planning methods. Majority (99.02\%) used temporary methods of family planning. Only one used permanent method. It revealed that $90.85 \%$ did not face any complications and only $9.15 \%$ faced difficulties during the use of contraceptives.
\end{abstract}

Key words : Family planning; Contraceptives; Condom; Vasectomy.

\section{INTRODUCTION}

Bangladesh is the seventh most populous country in the world. Over the past few decades, there have been efforts to hold back the rush of population growth. According to Bertrand Russel, "Those who in principle oppose birth control are either incapable of arithmetic or else in favour of war, pestilence and famine as permanent features of human life"1. So, as a responsible citizen we all should adopt family planning methods. The contraceptive methods may be broadly grouped into two classes. They are spacing methods and terminal methods. The modern methods are vas occlusion, immunocontraception, chemical methods ${ }^{2}$. But as developing country like Bangladesh, condom,coitus interrupts and vasectomy are frequently used methods. 
A husband is required to be supportive of the decisions and needs pertaining to the reproductive health of his wife. Their participation in family with planning and use of contraceptive is essential preventing sexually transmitted diseases. Even though some very cost effective methods are available in our country, their acceptance and participation in family planning still low.Lack of awareness and adequate knowledge are the most important reason. Men along with other special group like nonpregnant, non-lactating women have been identified as undeserved demographic groups under the HPSP and NIPHP ${ }^{3}$. Thus male have become an undeserved for many reasons both programmatic and cultural.

We need to focus on three areas: i) the promotion of male contraception and safe sexual practice to prevent STDS and AIDS ii) establishment of male only sexual clinics iii) carrying out of studies on the prevalence of STDS and treatment seeking behavior by $\mathrm{men}^{4}$. According to current data, the underlying cause is that the development of male contraceptive has not been so far increased in comparison to female contraceptives ${ }^{5}$. It demonstrates that the share of male methods to the total contraceptive prevalence rate is very low ${ }^{6}$. The picture of the whole mechanism which regulates fertility behavior is not clear ${ }^{7}$. To ease the burden, men should play greater role in contraceptive use as a joint and equal responsibility. We do not know much about men, because we have not asked. It is now, that we should begin ${ }^{8}$.

\section{MATERIALS AND METHODS}

This was a cross-sectional type of descriptive study. The study was conducted at a selected village called Darogarchala under Sreepur Upazilla of Gazipur district. The duration of study was from February 2010 to June 2010. The study population was married malebetween 20 to 60 years of age. Sample size was 380. Sample was taken purposively. Data was collected by face to face interview of the respondents by using interviews and administered questionnaire. It was duly pre-tested among married males of the said age group. Considering the objectives, questionnaire was formed consisting both open and close ended questions. The questionnaire contained 25 questions regarding contraceptive practice of the married male. The collected data were compiled and analyzed by using computer.

\section{RESULTS}

A total of 325 married males of age ranging 20 to 60 years were included in this study. About $60 \%$ of the respondents were in the age group 30-49. Among the respondents about $36 \%$ were illiterate and $28 \%$ had primary education. According their occupation about one third (34\%) were businessman, 19\% were service holder and 16\% were agricultural worker. Among the respondents majority of them (64.92\%) lived in single family and rest of them (35.08 \%) lived in joint family (Table 1). The monthly income of 144 respondents were within 1000 to $5000 \mathrm{Tk} .110$ of them earned 5001 to $1000 \mathrm{Tk}, 35$ earned
10001 to $15000 \mathrm{Tk}, 65$ earned 20001 to 25000 , nine of them earned more than $25000 \mathrm{Tk}$. Range of monthly income was 1000 -40000 in Tk. According to the age of marriage, majority of the respondents (45\%) were within the age of $20-24$. Regarding to have no. of living children about $50 \%$ (148) had $3-5$ children, only $6 \%$ had $>5$ children and $134(44.67 \%)$ had $1-2$ children (Table 2) where $n=300$. According their (respondents) wish to have more children $26.77 \%$ expressed their wish to have more children, whereas $73.23 \%$ were not willing to have any more children (Fig-1). Regarding awareness about family planning, among 325 respondents $76.3 \%$ were well aware of family planning and the rest $23.7 \%$ were not (Table 3 ) aware of family planning.

Among the 103 respondents (Who used) 102 used temporary methods and only one used permanent methods of family planning. Among the respondents, majority (320) were muslims.

Table 1 : Distribution of the respondents according to the type of family.

\begin{tabular}{lcc} 
Type of family & Number of respondents & percentage \\
Single & 211 & $64.92 \%$ \\
Joint & 114 & $35.8 \%$ \\
Total & 325 & $100 \%$ \\
\hline
\end{tabular}

Table 2 : Distribution of the respondents according to the number of their living children $(\mathrm{n}=300)$.

\begin{tabular}{ccc} 
Number of living children & Number of respondents & Percentage \\
$1-2$ & 134 & $44.67 \%$ \\
$3-5$ & 148 & $49.33 \%$ \\
75 & 18 & $6.0 \%$ \\
Total & 300 & $100 \%$ \\
\hline
\end{tabular}

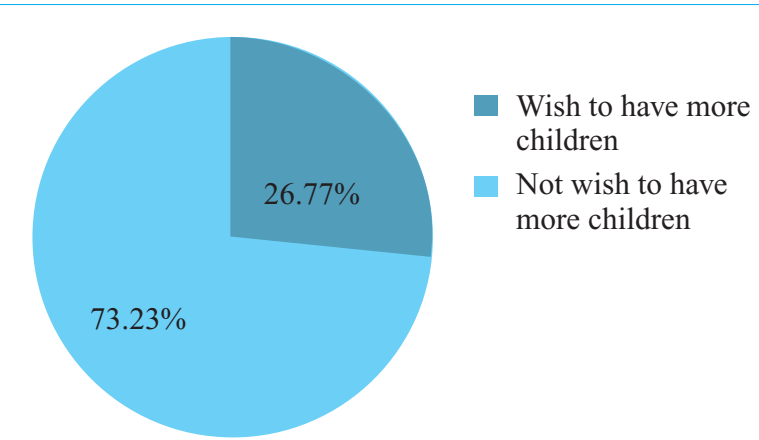

Figure 1: Distribution of the respondents according to their wish to have children.

Table 3 : Distribution of the respondents according to their awareness about family planning.

\begin{tabular}{lrr}
$\begin{array}{l}\text { Awareness about } \\
\text { family planning }\end{array}$ & Number of respondents & percentage \\
Yes & & \\
No & 248 & $76.3 \%$ \\
Total & 77 & $23.7 \%$ \\
\hline
\end{tabular}

Volume 15, Issue 1, January 2016 


\section{DISCUSSION}

Population explosion has been recognized as the number one problem by the government of Bangladesh. Observing the socio economic perspective of our country, man plays the key role socially and economically first as a husband, then father in the formation of the family, in the child education and in the health and nutrition of the family. A husband is required to be supportive of the decisions and needs pertaining to the reproductive health of his wife. Their participation in family planning and use of contraceptive is essential for preventing sexually transmitted diseases. This is the usual practice that the females are the ones who use contraceptive methods than males for maintaining their family size. In respect of age the study focused that among the total number of 325 respondents, the mean age of the respondents was 38.5 ( \pm SD 10.2). Among the respondents, majorities $(35.69 \%)$ of the respondents were illiterate and 5 were graduates. Maximum about 111 of the respondents were business man, 64 were labourers, 62 were service holders, 51 were farmers, $12(3 \%)$ were unemployed and the rest $(8 \%)$ were involved in other occupations. In other study, farming was the primary occupation of men in rural area, followed by business, day labour and monthly salaried job which showed dissimilarity with this study?

Among the 325 respondents, majorities 211 (About 65\%) of the family were from nuclear family and the rest were from joint family. Majority of the respondents fell in the low income category were in favour of family planning compared to negative attitude poverty was the primary 'Spur' for not wanting more children ${ }^{10}$. Another study conducted entitled "MEN AND FAMILY PLANNING in BANGLADESH" found that majority $(78.09 \%)$ respondents had 1 to 3 alive children and $22 \%$ of the respondents had more than 3 alive children which showed similarity with the study. The study revealed $26.77 \%$ of the respondents wished to have more children in future and $238(73.23 \%)$ wished not to have child in future. Comparing the data with that from the 1989 contraceptive prevalence survey repeated that fertility desires decreased somewhat. The percentage of men wanting more than 2 children in 1089 was 39 and wanting more than 3 children was 24 . Male attitudes were generally positive about FP and about small family size.
The majority of men with 3 or more children did not want to have any more ${ }^{11}$. This showed dissimilarity with the study. According to the data provided by the 1996-97 BDHS, nearby $70 \%$ of men reported that they had heard or seen a FP message in mass media. $58 \%$ of men heard a FP message on radio, while $46 \%$ saw a message on television ${ }^{12}$. Almost all of the respondents could name at least one family planning method but most of men could not name many specific methods ${ }^{10}$. Knowledge of family planning method among male was high in Bangladesh. Most of the husbands knew about at least one modern method of contraception. The study focused that 129 did not face any complications and 13 faced difficulties during use among the uses of contraceptives. The two major reasons mentioned in the study (Khan et al. ibid) for not accepting the permanent method were as i) Dislike of the method by husbands and wives ii) Fear of operation which was similar to the study among the respondents who use contraceptive methods were not facing any major difficulties and had a good compliance, which could open up a new horizon in the control of population explosion in future and have a profound impact on country's progress and development. It should be well understood by the male partners that the male methods of contraception are safer and easier to adopt.

\section{CONCLUSION}

Bangladesh is one of the most densely populated countries in the world. Every year this population is increasing. This population growth is now one of the major problems of our country. The study showed that the majority of the men were not aware about the various methods of family planning or were only partially aware. The government should extend more support to the health and family planning sector so that the goal can be achieved, because male methods are safer and economically cheap.

\section{DISCLOSURE}

All the authors declared no competing interest. 


\section{REFERENCES}

1. Park K. Park's Textbook of Preventive and Social Medicine. Jabalpur. M/S Banarsidas Bhanot. 2007 ; 19:358-359.

2. David I Handelsman. Male Contraceptive Publisher From Department of Reproductive Endocrinology and Andrology, University of Sidney, Australia. 2008; 1-6.

3. Ali Ashraf, Thomas T, Kane, Ahsan Shahriar, Barkay-E-Khuda. Male involvement in reproductive health services in Bangladesh: A review publisher by ICDOR.B, Centre for health and population Research. 1999; 1-5.

4. Terence H. Hull. Putting men in picture: Problems of male reproductive health in South East Asia published. 2001;178-185.

5. Masiur R, Rafiqul I and Martin A. Male Contraceptive in Rajshahi district in Bangladesh. Published by Department of Population Science and Human Resource and Development, University of Rajshahi, Bangladesh. 2008;15-19.

6. Monirul I Khan, Radheshyam Bairagi. Contraceptive use in Matlab with special focus on condoms: Socio Economic Correlates and Future Implications. Journal o Health and Population in Developing Countries. 2001; 16 - 22.

7. G R Verma and H. Rohini. Attitude of Spouse towards Family Planning: A Study among Married Men and Women of a Rural Community in West Godavari District, Andhra Pradesh. Department of Social Work, School of Distance Education, Andhra University. 2008;10(1):71-75.

8. Sidney Ruth Schuler, Syed M. Hashemi and Ann Hendrix Jenkins. Bangladesh's Family Planning Success Story: A Gender Perspective. 1995;21(4):133-166.

9. Terefe A Larson. Modern contraception use in Ethiopia: Does involving husbands make a difference? American Journal of Public Health. 1993; 83(11): 1567 - 1571.

10. Nancy J, Piet-Pelon. Male involvement: A challenge for the Bangladesh national family planning program, Policy Dialogue, Population Council, Bangladesh. 1996; 1 - 7 .

11. Debbie Donahoe. Men and Family Planning in Bangladesh: A Review of the Literature. The Population Council, Asia and Near East Operations Research and Technical Assistance Project. 1996; 1 - 13.

12. Kazi Jahid Hossain. Male involvement in family planning in Bangladesh: Factors constraining low use and the potential for augmenting the CPR. Published by Centre for Policy Dialogue. 2003; $1-29$. 